\title{
Preventing group B streptococcal infections: New recommendations
}

\author{
H Dele Davies MD MSc
}

$\mathrm{G}$ roup B streptococcus (GBS) has emerged over the past three decades as the most frequent infectious cause of mortality and morbidity among newborn infants in North America and Europe (1-3). Before the implementation of preventive guidelines (4), neonatal GBS disease occurred in 0.2 to five/1000 live births worldwide (2,5-9). Canadian rates ranged between 0.44 and 2.1/1000 live births in the early 1990 s, with a case fatality rate of $16.2 \%$ (7). There is also frequent significant morbidity that may include hearing loss, impaired vision and developmental problems (10). GBS is spread vertically from the mother to the neonate during the birthing process, and the gastrointestinal tract is the main reservoir for this organism. The vagina is colonized with GBS in approximately $10 \%$ to $30 \%$ of pregnant women $(11,12)$. Although there was agreement in the literature about the effectiveness of intrapartum antibiotic chemoprophylaxis $(13,14)$, there has been controversy on how to best identify which women should receive prophylaxis. Many different approaches were evaluated in theoretical models, but there was little empirical evidence to support one approach over another (15-19). The present note reviews the most recent data and alerts physicians to the soon-to-be-published consensus recommendations of the United States' Centers for Disease Control and Prevention (CDC) for neonatal GBS prevention (20). The recommendations are for universal prenatal screening for GBS colonization with the use of a risk factor-based approach only for specific situations in which there is uncertainty about the GBS status of the mother.

There have been a number of guidelines issued on neonatal GBS prevention since 1992. In Canada, the 1994 consensus policy statement by the Canadian Paediatric Society (21) and the Society of Obstetricians and Gynaecologists of Canada (22) recommended one of two approaches for the prevention of neonatal GBS. The first was a risk-based approach similar to one that was first recommended by the American College of Obstetricians and Gynaecologists in 1992 (23,24), while the second was a screening-based approach (at 26 to 28 weeks' gestation), which was initially recommended by the American Academy of Pediatrics in 1992 (25). Risk factors considered in the risk-based approach for prophylaxis include:

- preterm (less than 37 weeks' gestation) labour;

- term (37 weeks or more) labour with either prolonged rupture of membranes (more than $18 \mathrm{~h}$ ), or maternal fever higher than $38.0^{\circ} \mathrm{C}$;

- previous delivery of a newborn with GBS disease; and

- previously documented GBS bacteriuria.

In 1997, the Society of Obstetricians and Gynaecologists of Canada endorsed an American joint consensus guideline that recommended either later screening (at 35 to 37 weeks' gestation) or the risk-based approach $(8,26)$. These guidelines highlighted the best site to swab for maximum yield (combined vaginal-rectal) in the screening-based approach, and also recommend the use of selective enrichment broth, which increases the yield of GBS by up to $50 \%$ (27). Two studies in the 1990s documented that the yield of GBS from specimens that are self-collected by pregnant women was similar to that collected by the obstetric care provider $(28,29)$. The recommended antibiotic regimen was intravenous penicillin $\mathrm{G}$, (five million units initially, followed by 2.5 million units every $4 \mathrm{~h}$ ) or ampicillin ( $2 \mathrm{~g}$ initially, followed by $1 \mathrm{~g}$ every $4 \mathrm{~h}$ ) until delivery or labour stopped. It was recommended that women who have penicillin allergy receive clindamycin $900 \mathrm{mg}$ every $8 \mathrm{~h}$ or erythromycin $500 \mathrm{mg}$ every $6 \mathrm{~h}$ intravenously. Most recently, the Canadian Periodic Task Force on Preventive Health Care published a report on GBS prevention, recommending screening at 35 to 37 weeks' gestation, with intrapartum treatment of only those women who are colonized and also have a risk factor (30).

Since the introduction of the first set of guidelines, early onset neonatal GBS rates have been declining in North America, with rates as low as $0.25 / 1000$ births in Canada and the United States, and with case fatality rates of less 
than $10 \%(4,31,32)$. These declines were likely a result of modest implementation of both risk- and screening-based expert guidelines and improved laboratory detection practices $(31,33)$. Hospitals with a policy related to GBS have been more likely to have declines in early-onset disease than those without guidelines $(34,35)$. Hospitals with screeningbased approaches are more likely to comply with recommendations of current guidelines than hospitals that have risk-based approaches. With the risk-based approach, only $40 \%$ to $80 \%$ of preterm deliveries or deliveries with prolonged rupture of membranes were given intrapartum antibiotics (36-38). In contrast, about $90 \%$ or more of women who were managed under the screening-based policy had documented GBS screening, and similar numbers of GBS-positive women received intrapartum antibiotics (38-44). Indirect evidence for superior efficacy of the screening-based approach also comes from surveys of obstetric care physicians in Alberta and Toronto. These surveys indicated that physicians in Toronto were more likely to use the risk factor-based approach than were physicians in Alberta. Coincident with this finding, the incidence of neonatal GBS disease in Toronto was higher than that in Alberta, even though there have been substantial declines in both regions (31). The rates of late-onset GBS disease did not change during the same period $(4,32)$.

In spite of the declines in rates of early-onset disease, GBS is a leading infectious cause of morbidity and mortality among newborns in Canada and the United States. Since the release of the most recent CDC guidelines, there are new data to evaluate the effectiveness of the screening approach compared with the risk-based approach. A recent CDC-sponsored multistate study incorporated population-based surveillance into a sample survey population of more than 600,000 live births. This was the first large-scale direct comparison of the two prevention strategies. Analysis of this study showed that the screening-based approach was greater than $50 \%$ more effective than the risk-based approach (45). The protective effect of the screening approach persisted even after controlling for risk factors associated with early-onset GBS disease (eg, preterm delivery, prolonged rupture of membranes, young maternal age and black race). The investigators concluded that the benefit of screening resulted from two factors:

- by identifying GBS-colonized women without obstetric risk factors (18\% of all deliveries), screening was able to cover more of the at-risk population than the riskbased approach; and

- women who were GBS-positive among the screened cohort were also more likely to receive intrapartum antibiotics than women with obstetric risk factors in the risk cohort.

This suggests that, although improvements in implementation of the risk-based approach would lead to a further decline in the disease, this would not be as great as that under universal screening. This level II evidence for a large protective effect of prenatal GBS screening compared with the risk-based approach provides the basis for a soon-to-bereleased recommendation from the CDC that there be universal prenatal GBS screening (20). The risk-based approach would be reserved only for those women without the proper prenatal care or documentation of results. The recommendations also reinforce that being colonized with GBS in a previous pregnancy is not considered to be an indication for intrapartum prophylaxis in subsequent pregnancies; however, such women require repeat evaluation for prenatal colonization.

There have been concerns raised about the potential adverse effects of current chemoprophylactic strategies. Although the estimated risk of anaphylaxis to penicillin is approximately four $/ 100,000$ people taking penicillin, this has been reported as a result of GBS prophylaxis only once since 1996 (46). This likely relates to the fact that most adult women are aware of their risk of anaphylaxis, and can thus be given alternative medications. The other emerging concern is the development of resistance in GBS. There have been no reports of GBS that are resistant to penicillin or ampicillin. However, there are increasing reports of resistance of GBS to clindamycin and erythromycin in Canada and the United States, with rates ranging from 7\% to $25 \%$ for erythromycin to $3 \%$ to $15 \%$ for clindamycin (47-50). A recent study in Alberta reported resistance rates of $5.6 \%$ and $3.0 \%$ to erythromycin and clindamycin, respectively (39). Resistance to erythromycin is often, but not always, associated with clindamycin resistance. The minimum inhibitory concentrations of cefazolin, a firstgeneration, intravenously administered cephalosporin, was low among a sample of invasive American isolates from 1998 to 1999 (51). For these reasons, cefazolin (2 g load, then $1 \mathrm{~g}$ every $8 \mathrm{~h}$ intravenously until delivery) is now recommended as the antibiotic of second choice for women with a history of penicillin allergy who are not at high risk for anaphylaxis. Women who are at high risk for anaphylaxis should receive clindamycin and erythromycin if they have susceptible isolates. If neither clindamycin and erythromycin is an option, then vancomycin $(2 \mathrm{~g}$ load intravenously, then $1 \mathrm{~g}$ every $12 \mathrm{~h}$ intravenously) should be given.

There have also been concerns raised about the possibility of an increase in the incidence of early onset sepsis due to pathogens other than GBS, including resistant ones. This has not emerged as a problem. Most studies, including those that are population-based, suggest stable $(52-54)$ or declining (55) rates of non-GBS early-onset sepsis with the increased use of intrapartum antibiotic prophylaxis. Whereas some single hospital studies have noted increased rates or cases of neonatal sepsis caused by Esherichia coli, Gram-negative or ampicillin-resistant pathogens, these appear to be limited to preterm or low birthweight deliveries $(53,56,57)$. This is an area that requires ongoing monitoring, but the current benefits of prevention appear to outweigh the risks. 
In summary, current prevention strategies have resulted in a dramatic decline in both GBS and other neonatal sepsis rates. However, there is empirical evidence that the riskbased prevention approach is not as effective as the screening-based approach and, therefore, it can no longer be equally recommended, hence the new American guidelines. Reports of increasing resistance of GBS to erythromycin and clindamycin indicate that these drugs should be reserved as second line agents only in women who are known to have susceptible organisms. Penicillin (or ampicillin) is the first line agent, and cefazolin is the alternative for persons without a high likelihood of anaphylaxis. In patients who have a high probability of anaphylaxis to betalactams, vancomycin should be used.

\section{REFERENCES}

1. Allardice JG, Baskett TF, Seshia MM, Bowman N, Malazdrewicz R. Perinatal group B streptococcal colonization and infection. Am J Obstet Gynecol 1982;142:617-20.

2. Schuchat A, Deaver-Robinson K, Plikaytis BD, Zangwill KM, Mohle-Boetani J, Wenger JD. Multistate case-control study of maternal risk factors for neonatal group B streptococcal disease. The Active Surveillance Study Group. Pediatr Infect Dis J 1994;13:623-9.

3. Eickhoff T, Klein J, Daly A, Ingall D, Finland M. Neonatal sepsis and other infections due to group B beta hemolytic streptococci. N Engl J Med 1964;271:1221-8.

4. Schrag S, Zywicki S, Farley M, et al. Group B streptococcal disease in the era of intrapartum antibiotic prophylaxis. N Engl J Med 2000;342:15-20.

5. Weisman LE, Stoll BJ, Cruess DF, et al. Early-onset group B streptococcal sepsis: A current assessment. J Pediatr 1992;121:428-33.

6. Zangwill KM, Schuchat A, Wenger JD. Group B streptococcal disease in the United States, 1990: Report from a multistate active surveillance system. MMWR CDC Surveill Summ 1992;41:25-32.

7. Davies H, LeBlanc J, Bortolussi R, McGeer A, PICNIC. The Pediatric Investigators Collaborative Network on Infections in Canada (PICNIC) study of neonatal group B streptococcal infections in Canada. Paediatr Child Health 1999;4:257-63.

8. Centers for Disease Control and Prevention. Revised guidelines for prevention of early-onset group B streptococcal (GBS) infection. American Academy of Pediatrics Committee on Infectious Diseases and Committee on Fetus and Newborn. Pediatrics 1997;99:489-96.

9. Siegel JD, Cushion NB. Prevention of early-onset group B streptococcal disease: Another look at single-dose penicillin at birth. Obstet Gynecol 1996;87:692-8.

10. Schuchat A. Group B streptococcal disease in newborns: A global perspective on prevention. Biomed Pharmacother 1995;49:19-25.

11. Regan JA, Klebanoff MA, Nugent RP. The epidemiology of group B streptococcal colonization in pregnancy. Vaginal Infections and Prematurity Study Group. Obstet Gynecol 1991;77:604-10.

12. Davies H, Adair C, McGeer A, et al. Antibodies to capsular polysaccharides of group B streptococcus in pregnant women: Relationship to colonization status and infection in the neonate. J Infect Dis 2001;184:285-91.

13. Allen UD, Navas L, King SM. Effectiveness of intrapartum penicillin prophylaxis in preventing early-onset group B streptococcal infection: Results of a meta-analysis. CMAJ 1993;149:1659-65.

14. Ohlsson A, Myhr TL. Intrapartum chemoprophylaxis of perinatal group B streptococcal infections: A critical review of randomized controlled trials. Am J Obstet Gynecol 1994;170:910-7.

15. Rouse DJ, Goldenberg RL, Cliver SP, Cutter GR, Mennemeyer ST, Fargason C Jr. Strategies for the prevention of early-onset neonatal group B streptococcal sepsis: A decision analysis. Obstet Gynecol 1994;83:483-94.

16. Strickland DM, Yeomans ER, Hankins GD. Cost-effectiveness of intrapartum screening and treatment for maternal group B streptococci colonization. Am J Obstet Gynecol 1990;163:4-8.
Given these new American recommendations and the current situation in which there are multiple North American recommendations for GBS prevention from different groups, a multidisciplinary conference is being planned in Canada to provide official Canadian recommendations based on currently available data.

ACKNOWLEDGEMENTS: The Canadian Paediatric Society Infectious Diseases and Immunization Committee thanks Dr Stephanie Schrag of the Centers for Disease Control and Prevention, USA, for presenting her data to the Committee and for her expert review of this note.
17. Mohle-Boetani JC, Schuchat A, Plikaytis BD, Smith JD, Broome CV. Comparison of prevention strategies for neonatal group $B$ streptococcal infection. A population-based economic analysis. JAMA 1993;270:1442-8.

18. Garland SM, Kelly N. Early-onset neonatal group B streptococcal sepsis: Economics of various prevention strategies. Med J Australia 1995;162:413-7.

19. Benitz WE, Gould JB, Druzin ML. Preventing early-onset group B streptococcal sepsis: Strategy development using decision analysis. Pediatrics 1999;103:e76.

20. Centers for Disease Control and Prevention. Revised Consensus Guidelines for Prevention of GBS Infection. MMWR Morb Mortal Wkly Rep 2002. (In press)

21. Canadian Pediatric Society and the Society of Obstetricians and Gynecologists of Canada. The prevention of early-onset group B streptococcal infections in the newborn [Consensus Statement]. Can J Infect Dis 1994;5:251-6.

22. Society of Obstetricians and Gynaecologists of Canada and Canadian Paediatric Society. National consensus statement on the prevention of early onset group B streptococcal infections in the newborn. J Soc Obstet Gynaecol Can 1994;16:2271-8.

23. American College of Obstetricians and Gynecologists. Group B streptococcal infections in pregnancy. ACOG Technical Bulletin Number 170 - July 1992. Int J Gynaecol Obstet 1993;42:55-9.

24. American College of Obstetricians and Gynecologists. Universal antepartum screening for maternal GBS not recommended. ACOG Newsletter 1993;Sect. 1-2.

25. American Academy of Pediatrics Committee on Infectious Diseases. American Academy of Pediatrics Committee on Infectious Diseases and Committee on Fetus and Newborn: Guidelines for prevention of group B streptococcal (GBS) infection by chemoprophylaxis. Pediatrics 1992;90:775-8.

26. Society of Obstetricians and Gynaecologists of Canada. Statement on the prevention of early onset group B streptococcal infections in newborns. J Soc Obstet Gynaecol Can 1997;19:419-20.

27. Centers for Disease Control and Prevention. Laboratory practices for prenatal Group B streptococcal screening and reporting Connecticut, Georgia, and Minnesota, 1997-1998. MMWR Morb Mortal Wkly Rep 1999;48:426-8.

28. Molnar P, Biringer A, McGeer A, McIsaac W. Can pregnant women obtain their own specimens for group B streptococcus? A comparison of maternal versus physician screening. The Mount Sinai GBS Screening Group. Family Practice 1997;14:403-6.

29. Mercer BM, Taylor MC, Fricke JL, Baselski VS, Sibai BM. The accuracy and patient preference for self-collected group B streptococcus cultures. Am J Obstet Gynecol 1995;173:1325-8.

30. The Canadian Task Force on Preventive Health Care. Prevention of group B streptococcal infection in newborns: Recommendation statement from the Canadian Task Force on Preventive Health Care. CMAJ 2002;166:928-30.

31. Davies HD, Adair CE, Schuchat A, Low DE, Sauve RS, McGeer A. Physicians' prevention practices and incidence of neonatal group $B$ streptococcal disease in 2 Canadian regions. CMAJ 2001;164:479-85. 
32. Davies HD, Raj S, Adair C, Robinson J, McGeer A. Populationbased active surveillance for neonatal group B streptococcal infections in Alberta, Canada: Implications for vaccine formulation. Pediatr Infect Dis J 2001;20:879-84.

33. Davies HD, Adair CE, Partlow ES, Sauve R, Low DE, McGeer A. Two-year survey of Alberta laboratories processing of antenatal group B streptococcal (GBS) screening specimens: Implications for GBS screening programs. Diagn Microbiol Infect Dis 1999;35:169-76.

34. Factor SH, Whitney CG, Zywicki SS, Schuchat A. Effects of hospital policies based on 1996 group B streptococcal disease consensus guidelines. The Active Bacterial Core Surveillance Team. Obstet Gynecol 2000;95:377-82.

35. Goldenberg E, Davies H, Landry L, The Toronto GBS study Group, The Toronto Bacterial Invasive Diseases Network, McGeer A. Hospital prevention policies and the incidence of early onset group B streptococcal (GBS) disease. 38th Interscience Conference on Antimicrobial Agents and Chemotherapy. San Diego, September 24 to $27,1998$.

36. Lieu TA, Mohle-Boetani JC, Ray GT, Ackerson LM, Walton DL. Neonatal group B streptococcal infection in a managed care population. Perinatal Group B Streptococcal Infection Study Group. Obstet Gynecol 1998;92:21-7.

37. Factor SH, Levine OS, Nassar A, et al. Impact of a risk-based prevention policy on neonatal group B streptococcal disease. Am J Obstet Gynecol 1998;179:1568-71.

38. Hafner E, Sterniste W, Rosen A, et al. Group B streptococci during pregnancy: A comparison of two screening and treatment protocols. Am J Obstet Gynecol 1998;179:677-81.

39. Spaetgens R, DeBella K, Ma D, Robertson S, Mucenski M, Davies HD. Perinatal antibiotic usage and changes in colonization and resistance rates of group B streptococcus and other pathogens. Obstet Gynecol 2002. (In press)

40. Davis RL, Hasselquist MB, Cardenas V, et al. Introduction of the new Centers for Disease Control and Prevention group B streptococcal prevention guideline at a large west coast health maintenance organization. Am J Obstet Gynecol 2001;184:603-10.

41. Jeffery HE, Moses LM. Eight-year outcome of universal screening and intrapartum antibiotics for maternal group B streptococcal carriers. Pediatrics 1998;101:E2.

42. Cheon-Lee E, Amstey MS. Compliance with the Centers for Disease Control and Prevention antenatal culture protocol for preventing group B streptococcal neonatal sepsis. Am J Obstet Gynecol 1998;179:77-9.

43. Katz V, Moos M, Cefalo R, Thorp J, Bowes W, Wells S. Group B streptococci: Results of a protocol of antepartum screening and intrapartum treatment. Am J Obstet Gynecol 1994;170:521-6.
44. Brozanski BS, Jones JG, Krohn MA, Sweet RL. Effect of a screeningbased prevention policy on prevalence of early-onset group B streptococcal sepsis. Obstet Gynecol 2000;95:496-501.

45. Schrag SJ, Phil D, Zell ER. A Population-based comparison of strategies to prevent early-onset group B streptococcal disease in neonates. N Engl J Med 2002;347:233-9.

46. Dunn AB, Blomquist J, Khouzami V. Anaphylaxis in labor secondary to prophylaxis against group B Streptococcus. A case report. J Repro Med 1999;44:381-4.

47. McGavin M, McGeer A, De Azavedo JC, et al. Emergence of erythromycin and clindamycin resistance in group B streptococci (GBS) associated with neonatal disease in Toronto, Canada. 39th Interscience Conference on Antimicrobial Agents and Chemotherapy (ICAAC). San Francisco, September 26 to 29, 1999.

48. Andrews JI, Diekema DJ, Hunter SK, et al. Group B streptococci causing neonatal bloodstream infection: Antimicrobial susceptibility and serotyping results from SENTRY centers in the Western Hemisphere. Am J Obstet Gynecol 2000;183:859-62.

49. Lin FY, Azimi PH, Weisman LE, et al. Antibiotic susceptibility profiles for group B streptococci isolated from neonates, 1995-1998. Clin Infect Dis 2000;31:76-9.

50. Bland ML, Vermillion ST, Soper DE, Austin M. Antibiotic resistance patterns of group B streptococci in late third-trimester rectovaginal cultures. Am J Obstet Gynecol 2001;184:1125-6.

51. Centers for Disease Control and Prevention. Early-onset group B streptococcal disease, United States, 1998-1999. MMWR Morb Mortal Wkly Rep 2000;49:793-6.

52. Main EK, Slagle T. Prevention of early-onset invasive neonatal group B streptococcal disease in a private hospital setting: The superiority of culture-based protocols. Am J Obstet Gynecol 2000;182:1344-54.

53. Baltimore RS, Huie SM, Meek JI, Schuchat A, O’Brien KL. Earlyonset neonatal sepsis in the era of group B streptococcal prevention. Pediatrics 2001;108:1094-8.

54. Cordero L, Sananes M, Ayers L. Bloodstream infections in a neonatal intensive care unit: 12 years' experience with an antibiotic control program. Infect Control Hospital Epidemiol 1999;20:242-6.

55. Isaacs D, Royle JA. Intrapartum antibiotics and early onset neonatal sepsis caused by group B Streptococcus and by other organisms in Australia. Australasian Study Group for Neonatal Infections. Pediatr Infect Dis J 1999;18:524-8.

56. Joseph TA, Pyati SP, Jacobs N. Neonatal early-onset Escherichia coli disease. The effect of intrapartum ampicillin. Arch Pediatr Adolesc Med 1998;152:35-40.

57. Towers CV, Carr MH, Padilla G, Asrat T. Potential consequences of widespread antepartal use of ampicillin. Am J Obstet Gynecol 1998;179:879-83.

\section{CANADIAN PAEDIATRIC SOCIETY, INFECTIOUS DISEASES AND IMMUNIZATION COMMITTEE}

Members: Drs Upton Allen, The Hospital for Sick Children, Toronto, Ontario; Dr H Dele Davies, Division of Infectious Diseases, Alberta Children's Hospital, Calgary, Alberta; Joanne Embree, The University of Manitoba, Winnipeg, Manitoba (chair); Joanne Langley, Department of Pediatrics, IWK Health Centre, Halifax, Nova Scotia; Mireille Lemay, Department of Infectious Diseases, Sainte-Justine Hospital, Montreal, Quebec; Gary Pekeles, The Montreal Children's Hospital, Montreal, Quebec (director responsible)

Consultants: Drs Noni MacDonald, Faculty of Medicine, Dalhousie University, Halifax, Nova Scotia; Victor Marchessault, Cumberland, Ontario Liaisons: Drs Scott Halperin, Department of Pediatrics, IWK Health Centre, Halifax, Nova Scotia (IMPACT); Susan King, Division of Infectious Diseases, The Hospital for Sick Children, Toronto, Ontario (Canadian Paediatric AIDS Research Group); Monique Landry, Direction de la santé publique de Laval, Laval, Quebec (Public Health); Larry Pickering, Centre for Pediatric Research, Norfolk, Virginia (American Academy of Pediatrics)

Principal author: Dr H Dele Davies, Division of Infectious Diseases, Alberta Children's Hospital, Calgary, Alberta

The recommendations in this statement do not indicate an exclusive course of treatment or procedure to be followed. Variations, taking into account individual circumstances, may be appropriate. This article also appears in Paediatr Child Health 2002;7(6)380-383. 


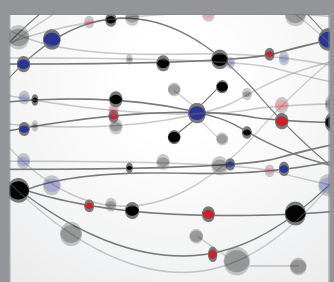

The Scientific World Journal
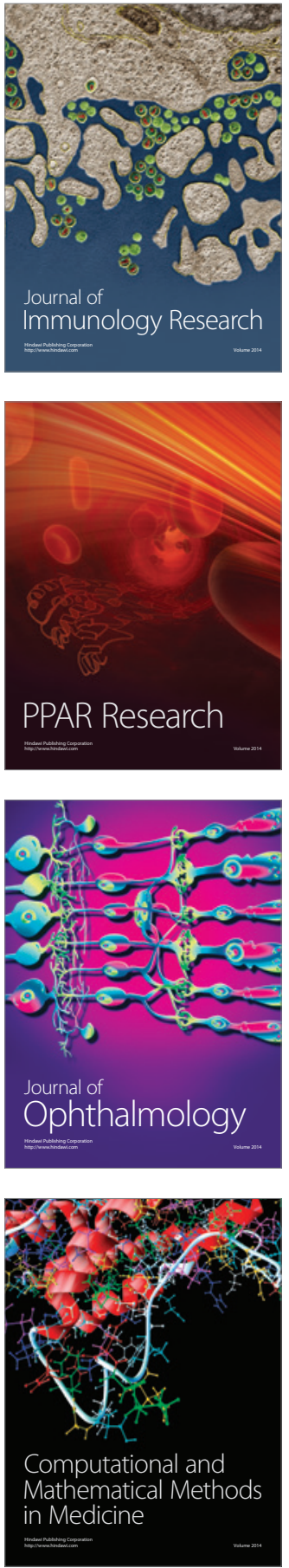

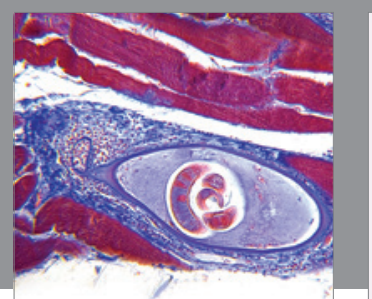

Gastroenterology Research and Practice

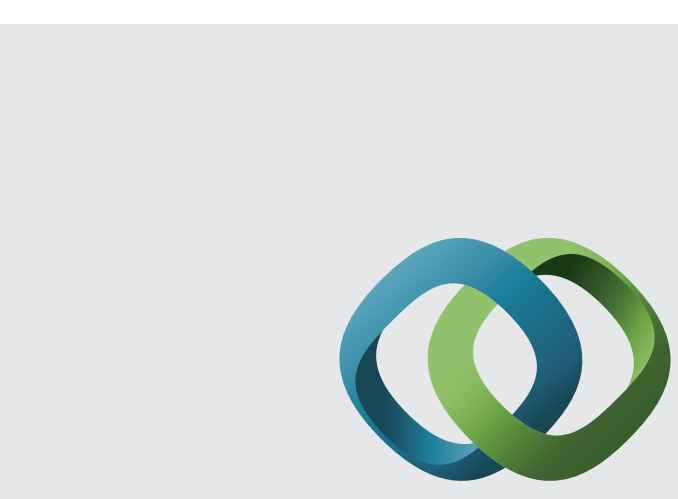

\section{Hindawi}

Submit your manuscripts at

http://www.hindawi.com
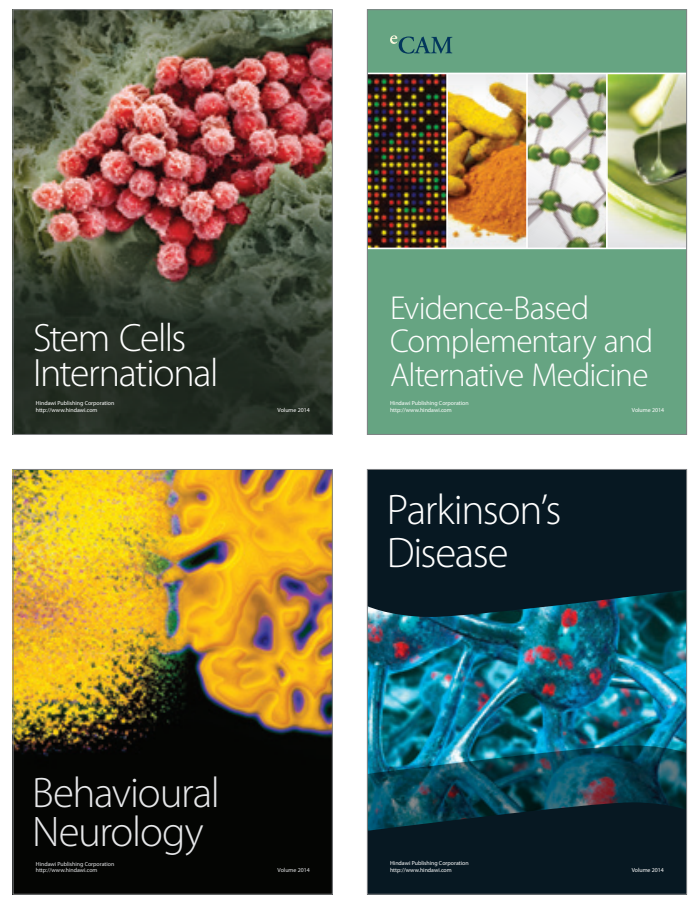
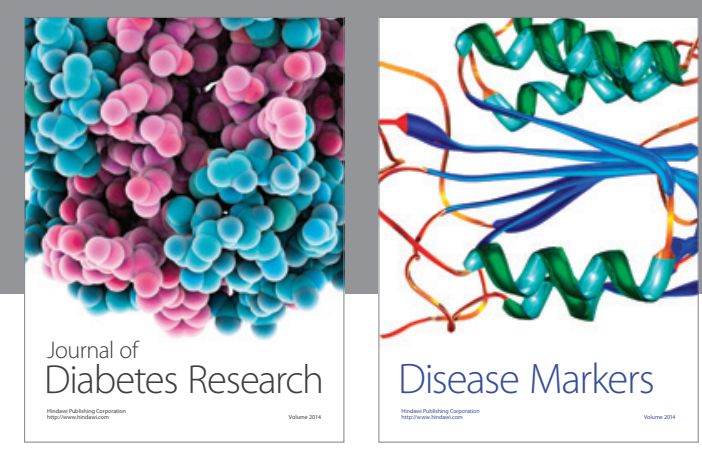

Disease Markers
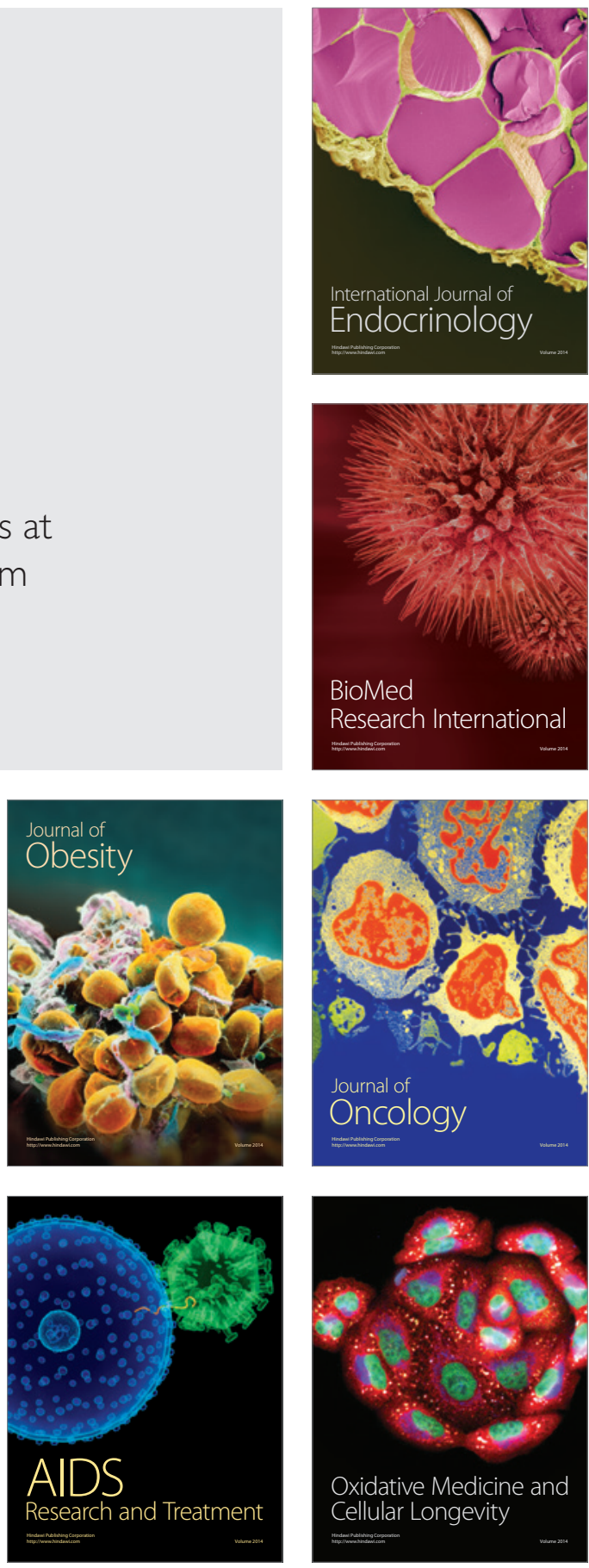